\title{
Article \\ Evolutionary Integrated Heuristic with Gudermannian Neural Networks for Second Kind of Lane-Emden Nonlinear Singular Models
}

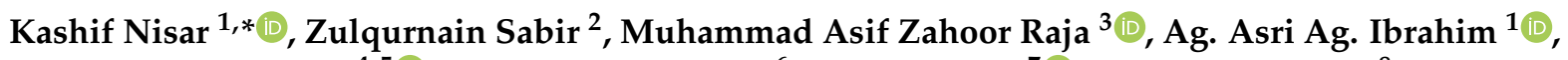 \\ Joel J. P. C. Rodrigues ${ }^{4,5}\left(\mathbb{D}\right.$, Adnan Shahid Khan ${ }^{6}$, Manoj Gupta ${ }^{7} \mathbb{C}$, Aldawoud Kamal ${ }^{8}$ and Danda B. Rawat ${ }^{9} \mathbb{C}$ \\ Citation: Nisar, K.; Sabir, Z.; Zahoor \\ Raja, M.A.; Ag. Ibrahim, A.A.; \\ Rodrigues, J.J.P.C.; Shahid Khan, A.; \\ Gupta, M.; Kamal, A.; Rawat, D.B. \\ 1 Faculty of Computing and Informatics, Universiti Malaysia Sabah, Jalan UMS, Kota Kinabalu, \\ Sabah 88400, Malaysia; awgasri@ums.edu.my \\ 2 Department of Mathematics and Statistics, Hazara University, Mansehra 21120, Pakistan; \\ zulqurnain_maths@hu.edu.pk \\ 3 Future Technology Research Center, National Yunlin University of Science and Technology, \\ 123 University Road, Section 3, Douliou, Yunlin 64002, Taiwan; rajamaz@yuntech.edu.tw \\ 4 Post-Graduation Program in Electrical Engineering, Federal University of Piauí (UFPI), \\ Teresina-PI 64049-550, Brazil; joeljr@ieee.org \\ 5 Covilhã Delegation, Instituto de Telecomunicações, 6201-001 Covilhã, Portugal \\ 6 Faculty of Computer Science and Information Technology, Universiti Malaysia Sarawak, \\ Kota Samarahan 94300, Malaysia; skadnan@unimas.my \\ 7 Department of Electronics and Communication Engineering, JECRC University Jaipur, \\ Rajasthan 303905, India; manojgupta35@yahoo.co.in \\ 8 Department of Mathematics and Statistics, Mutah University Jordan, Mu'tah 61710, Jordan; \\ aldawoud@mutah.edu.jo \\ 9 Data Science and Cybersecurity Center, Dept of Electrical Engineering and Computer Science, Howard \\ University, Washington, DC 20059, USA; db.rawat@ieee.org \\ * Correspondence: kashif@ums.edu.my
} Evolutionary Integrated Heuristic with Gudermannian Neural Networks for Second Kind of Lane-Emden Nonlinear Singular Models. Appl. Sci. 2021, 11, 4725. https://doi.org/10.3390/app11114725

Academic Editors: Christos Bouras and Federico Divina

Received: 18 January 2021

Accepted: 20 April 2021

Published: 21 May 2021

Publisher's Note: MDPI stays neutra with regard to jurisdictional claims in published maps and institutional affiliations.

Copyright: (c) 2021 by the authors. Licensee MDPI, Basel, Switzerland. This article is an open access article distributed under the terms and conditions of the Creative Commons Attribution (CC BY) license (https:// creativecommons.org/licenses/by/ $4.0 /)$.
Abstract: In this work, a new heuristic computing design is presented with an artificial intelligence approach to exploit the models with feed-forward (FF) Gudermannian neural networks (GNN) accomplished with global search capability of genetic algorithms (GA) combined with local convergence aptitude of active-set method (ASM), i.e., FF-GNN-GAASM to solve the second kind of Lane-Emden nonlinear singular models (LE-NSM). The proposed method based on the computing intelligent Gudermannian kernel is incorporated with the hidden layer configuration of FF-GNN models of differential operatives of the LE-NSM, which are arbitrarily associated with presenting an error-based objective function that is used to optimize by the hybrid heuristics of GAASM. Three LE-NSM-based examples are numerically solved to authenticate the effectiveness, accurateness, and efficiency of the suggested FF-GNN-GAASM. The reliability of the scheme via statistical valuations is verified in order to authenticate the stability, accuracy, and convergence.

Keywords: Gudermannian kernel; Lane-Emden model; Gudermannian neural networks; active-set method; numerical solutions; genetic algorithms

\section{Introduction}

The singular models have many appreciated applications in physics, physiology, engineering, and mathematics. The paramount Lane-Emden model is a historical model, which is famous due to singularity and presented by Lane and Emden [1,2] a few centuries ago by working on the performance of thermal gas and the state of thermodynamics [3]. The generic form of the Lane-Emden nonlinear singular models (LE-NSM) is written as [4]:

$$
\left\{\begin{array}{l}
u^{\prime \prime}(t)+\frac{\eta}{t} u^{\prime}(t)+g(t, u)=0, \eta \geq 0,0<t \leq 1, \\
u(0)=I_{1}, u^{\prime}(0)=I_{2}
\end{array}\right.
$$


where the shape factor is $\eta, g(t, u)$ is the real-valued continuous function, and $I_{1}$ and $I_{2}$ represent constants values.

The LEM singular nonlinear models define a collection of phenomena in the gaseous star density [5], the physical area of science [6], the theory of electromagnetic [7], stellar construction system [8], morphogenesis [9], physics-based mathematical model [10], oscillating magnetic areas [11], an isotropic medium [12] and models of dusty fluid [13]. Solving the singular models is found to be grim and tough due to a singular point at the origin. Few analytical and numerical schemes are accessible to handle such singular nonlinear models are presented in these references [14-16].

All presented above schemes have their individual sensitivity, potential, efficiency, and correctness, as well as weaknesses, flaws, and demerits over each other. The extensive computing heuristic approach potential is to solve the singular systems applying the widespread capacity of artificial neural networks (ANNs) collectively with local and global based search approaches [17-23]. Few noteworthy illustrations contain neuro-intelligent computing approach to study the dynamics of convective heat transfer involving carbon nanotubes [24], dusty plasma nonlinear model [25], model of mosquito release in the heterogeneous atmosphere [26], Navier Stokes problems [27], singular functional differential model [28], HIV infection system of CD4+ T cells [29], plasma-based physics investigations [30], Thomas-Fermi singular system [31], prey-predator biological system [32], nanotechnology [33], killing well control system [34], biological model based on corneal shape [35], Jeffery Hamel flow problem [36], parameter estimation in biodiesel studies [37] and model of atomic physics model [38]. These potential applications proved the significance of the stochastic solvers on the basis of stability, convergence, and exactitude. Therefore, the novel design of the Gudermannian neural network (GNN) is exploited using the genetic algorithm (GA) and active-set method, i.e., GNN-GAASM for the second kind of LE-NSM.

The basic aim of this study is to solve the second kind of LE-NSM by introducing a new intelligent scheme based on combined heuristics of GNN-GAASM. Few pioneering topographies of the designed GNN-GAASM are briefly listed as follows:

- A novel GNN-GAASM computing-based stochastic solver is designed, implemented, and exploited using differential continuous mapping of GNNs together with optimization with the hybrid combined heuristics of GAs and ASM;

- The presented GNN-GAASM solver is tested accurately to effectively solve the three different examples of the nonlinear singular model;

- The overlapping of the results obtained by the GNN-GAASM from the exact solutions show the consistency, precision, and correctness of GNN-GAASM to approximate the solution of the second kind of the LE-NSMs;

- The obtained outcomes of proposed GNN-GAASM for multiple executions via different performance measures of mean, Nash Sutcliffe efficiency (NSE), semi-interquartile range (S.I.R), median, and variance account for (VAF) further enhanced the competence of the designed GNN-GAASM.

The other paper parts are provided as: Section 2 describes the model structure, Section 3 gives the optimization model detail, Section 4 gives the information of performance indices, Section 5 relates the detail of numerical solutions together with interpretations of the outcome. The conclusion details and future research clarifications are given in the final section.

\section{Methodology}

The current section describes the GNN operators, which are designed with the necessary explanation to solve the second kind of LE-NSM. The operations of the differential system, merit function (MF), and optimization procedures through the GAASM are also discussed. 


\subsection{Designed Methodology: GNN}

The neural networks are familiar with delivering standardized as well as reliable solutions for numerous applications arising in a variety of diverse fields. In this modeling, $\hat{u}(t)$ shows the obtained results through GNN-GAASM and its $n$th derivatives, written as:

$$
\begin{gathered}
\hat{u}(t)=\sum_{k=1}^{m} q_{k} z\left(w_{k} t+p_{k}\right) \\
\hat{u}^{(n)}=\sum_{i=1}^{m} q_{k} z^{(n)}\left(w_{k} t+p_{k}\right),
\end{gathered}
$$

where, $n$ and $m$ indicate the derivative order and number of neurons, respectively. The MF is $z$, while, $q, w, p$ are the unknown weight vectors, which are defined as $\boldsymbol{W}=[\boldsymbol{q}, \boldsymbol{w}, \boldsymbol{p}]$, for $\boldsymbol{q}=\left[q_{1}, q_{2}, q_{3}, \ldots, q_{m}\right], \boldsymbol{w}=\left[w_{1}, w_{2}, w_{3}, \ldots, w_{m}\right]$ and $\boldsymbol{p}=\left[p_{1}, p_{2}, p_{3}, \ldots, p_{m}\right]$. The Gudermannian function (GF) is written as:

$$
u(t)=2 \tan ^{-1}[\exp (t)]-\frac{1}{2} \pi
$$

Using the GF given in the above equation, the approximate continuous mapping of differential operations is written as:

$$
\begin{gathered}
\hat{u}(t)=\sum_{k=1}^{m} q_{k}\left(2 \tan ^{-1} e^{\left(w_{k} t+p_{k}\right)}-\frac{\pi}{2}\right), \\
\hat{u}^{\prime}(t)=\sum_{k=1}^{m} 2 q_{k} w_{k}\left(\frac{e^{\left(w_{k} t+p_{k}\right)}}{1+\left(e^{\left(w_{k} t+p_{k}\right)}\right)^{2}}\right), \\
\hat{u}^{\prime \prime}(t)=\sum_{k=1}^{m} 2 q_{k} w_{k}^{2}\left(\frac{e^{\left(w_{k} t+p_{k}\right)}}{1+\left(e^{\left(w_{k} t+p_{k}\right)}\right)^{2}}-\frac{2 e^{\left(w_{k} t+p_{k}\right)^{3}}}{\left(1+\left(e^{\left(w_{k} t+p_{k}\right)}\right)^{2}\right)^{2}}\right)
\end{gathered}
$$

For solving the second kind of the LE-NSM, the formulation of MF using the mean squared error metric is given as:

$$
E=E_{1}+E_{2},
$$

where $E$ denotes an unsupervised error function associated to the second kind of the LE$\mathrm{NSM}$, whereas, $E_{1}$ and $E_{2}$ are the respective error functions linked to boundary conditions of the model (1) as:

$$
\begin{gathered}
E_{1}=\frac{1}{N} \sum_{k=1}^{N}\left(\hat{u}^{\prime \prime}\left(t_{k}\right)+\frac{\eta}{t_{k}} \hat{u}^{\prime}\left(t_{k}\right)+g\left(t_{k}, u\left(t_{k}\right)\right)\right)^{2}, \\
E_{2}=\frac{1}{2}\left(\left(\hat{u}_{0}-I_{1}\right)^{2}+\left(\hat{u}_{0}^{\prime}-I_{2}\right)^{2}\right),
\end{gathered}
$$

where $N h=1, \hat{u}_{k}=u\left(t_{k}\right), g(t, u)=g\left(t_{k}, u\left(t_{k}\right)\right)$, and $t_{k}=k h$.

\subsection{Network Optimization}

The numerical solutions of the second kind of LE-NSM are acquired to optimize the GNN by applying the hybrid computing scheme, i.e., GAASM.

GA is one of the intelligent evolutionary computing schemes that is based on natural development. In the 7th decade of the 19th century, GA is discovered with the innovator's work of Holland [39], and later it is employed as a key leading derivative to optimize the models based on constrained/un-constrained arrangements. GA works through the optimal process of mutation, selection, heuristic, and crossover. GA is widely applied in many areas such as robotics, astrophysics, optics, digital communication, bioinformatics, signal processing, financial mathematics, nuclear power system, economics, chemical industry, and materials. Some recent submissions of GAs that works as an optimization model are 
wind power model [40], heart disease prediction [41], intrusion detection performance model [42], energy managing systems [43], metal-organic constructions [44], heterogeneous celebration [45], heartbeat systems [46], a study of military systems [47], aquatic weed model [48]. These presented applications inspired the authors to apply the GA as an optimization process using the GNN to find the approximate outputs of the second kind of LE-NSM.

GA hybridizes with local search ASM, i.e., local search approach to use the quick convergence by assigning the best GA values as a start/initial point. Hence, ASM is suitable to regulate the parameters. ASM has been implemented in many recent submissions, such as trade and industry load dispatch models [49], short-term hydrothermal supervision [50], bipedal walking robot dynamics [51], economic multiproduct manufacture [52], LNG process [53], model of heating in the thermal blow frame cycling [54], aircraft transportation [55], wind turbine support structures [56] and quadratic convex bilevel programming models [57]. In this study, the combination of GAASM is implemented to solve the second kind of LE-NSM, and the optimization process of GAASM is provided in Table 1. The variety of the procedure is introduced for selection, i.e., stochastic uniform, remainder, roulette, and tournament, for mutation, i.e., Gaussian, uniform and adaptive feasible, as well as for crossover, scattered, single point, two points, intermediate, arithmetic and heuristic, however, we set stochastic uniform for the selection, heuristics for the crossover and adaptive feasible for mutation. These parameter settings are adopted after a lot of experiments, knowledge, experience, and performance advantages on different applications in the presented study.

Table 1. Pseudocode for the optimization GNN-GAASM for solving the second kind of LE-NSM.

\section{GA procedure}

Inputs: Indicate the chromosomes with equal number of model entries as: $W=[q, w, p]$

Population: The chromosomes set is signified as: $\boldsymbol{q}=\left[q_{1}, q_{2}, q_{3}, \ldots, q_{m}\right], \boldsymbol{w}=\left[w_{1}, w_{2}, w_{3}, \ldots, w_{m}\right]$ and $\boldsymbol{p}=\left[p_{1}, p_{2}, p_{3}, \ldots, p_{m}\right]$.

Output: GA best global weights are symbolized as $\boldsymbol{W}_{\mathrm{GA}-\text { Best }}$

Initialization: Create a $W$ called a weight vector containing real entries to select a chromosome. 'W' is applied to design an initial population with [Population Size = 270]. Regulate the values of generation as well as assertion for the ga optimset.

Fitness valuation: Accomplished the fitness $(E)$ in the population for all the weight vectors using the Equations (5)-(7).

Stopping criteria: Terminate, when any of the value is achieved

- $\left[\right.$ Fit $\left.=10^{-19}\right]$, [StallLimit $\left.=100\right]$, [Generations $\left.=75\right],\left[\right.$ TolCon $=$ TolFun $\left.=10^{-22}\right]$,

- $\quad$ Other: default

Move to storage, when meets the stopping standards

Ranking: Rank the weight vector of Population for the brilliance of Fit Reproduction:

- $\quad$ [Selection = @ uniform],

- [Crossover:@ heuristic],

- [Mutations:@adapt feasible].

Store: Save $W_{\mathrm{GA}-\mathrm{Best}}, E$, Generations, function counts and time for the existing GAs runs. GA process Ends 
Table 1. Cont.

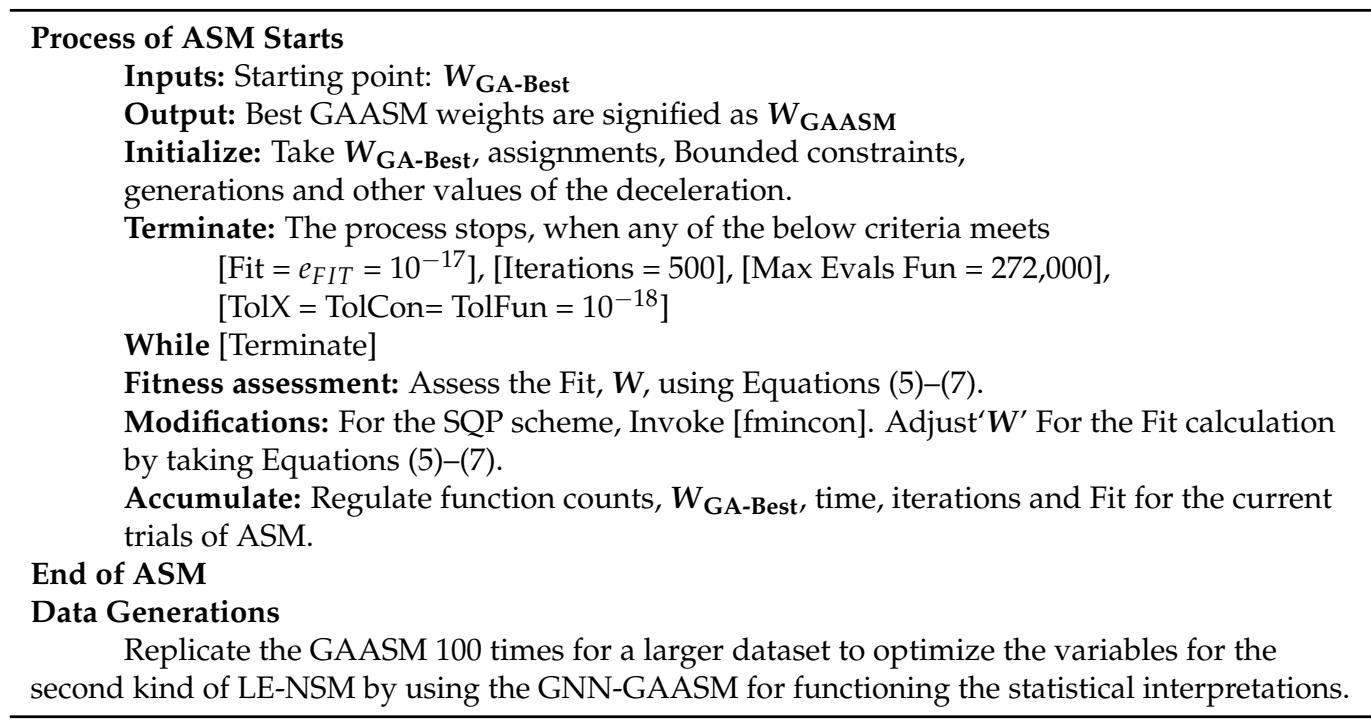

\section{Performance Procedures}

The demonstration actions to solve the second kind of LE-NSM to authenticate the GAASM are constructed in terms of the Nash Sutcliffe efficiency (NSE) and variance account for (VAF), mathematically given as:

$$
\begin{aligned}
& \text { NSE }=\left\{1-\frac{\sum_{k=1}^{n}\left(u_{k}-\hat{u}_{k}\right)^{2}}{\sum_{k=1}^{n}\left(u_{k}-\bar{u}_{k}\right)^{2}}, \bar{u}_{k}=\frac{1}{n} \sum_{k=1}^{n} u_{k},\right. \\
& \text { ENSE }=1-\mathrm{NSE} . \\
& \left\{\begin{array}{l}
\text { VAF }=\left(1-\frac{\operatorname{var}\left(u_{k}-\hat{u}_{k}\right)}{\operatorname{var}\left(u_{k}\right)}\right) \times 100, \\
E V A F=|V A F-100|,
\end{array}\right.
\end{aligned}
$$

\section{Result and Simulations}

The comprehensive simulations for the numerical outcomes using GNN-GAASM to solve the second kind of LE-NSM are presented in this section.

Problem I: Consider the second kind of LE-NSM involving exponential functions is written as:

$$
\left\{\begin{array}{l}
u^{\prime \prime}(t)+\frac{0.5}{t} u^{\prime}(t)+\left(e^{2 u(t)}-0.5 e^{u(t)}\right)=0, \quad t \in(0,1) \\
u(0)=\ln (2), \quad u(1)=0
\end{array}\right.
$$

For the above equation, the MF is given as follow:

$$
E=\frac{1}{N} \sum_{k=1}^{N}\left(\begin{array}{c}
t_{k} \hat{u}^{\prime \prime}\left(t_{k}\right)+0.5 \hat{u}^{\prime}\left(t_{k}\right)+ \\
t_{k}\left(e^{2 \hat{u}\left(t_{k}\right)}-0.5 e^{\hat{u}\left(t_{k}\right)}\right)
\end{array}\right)^{2}+\frac{1}{2}\left(\left(\hat{u}_{0}-\ln (2)\right)^{2}+\left(\hat{u}_{N}\right)^{2}\right) .
$$

The exact solution is $\ln \left(\frac{2}{\left(t^{2}+1\right)}\right)$.

Problem II: Consider the second kind of LE-NSM is written as:

$$
\left\{\begin{array}{l}
u^{\prime \prime}(t)+\frac{2}{t} u^{\prime}(t)+u^{5}(t)=0, \quad t \in(0,1) \\
u(1)=0.75, \quad u^{\prime}(0)=0
\end{array}\right.
$$


For the above equation, the MF is given as follow:

$$
\begin{aligned}
E= & \frac{1}{N} \sum_{k=1}^{N}\left(t_{k} \hat{u}^{\prime \prime}\left(t_{k}\right)+2 \hat{u}^{\prime}\left(t_{k}\right)+t_{k} \hat{u}^{5}\left(t_{k}\right)\right)^{2} \\
& +\frac{1}{2}\left(\left(\hat{u}_{N}-0.75\right)^{2}+\left(\hat{u}_{0}^{\prime}\right)^{2}\right) .
\end{aligned}
$$

The exact solution is $\sqrt{\frac{3}{t^{2}+3}}$.

Problem III: Consider the second kind of LE-NSM having an exponential function is written as:

$$
\left\{\begin{array}{l}
u^{\prime \prime}(t)+\frac{1}{t} u^{\prime}(t)+e^{u(t)}=0, t \in(0,1) \\
u^{\prime}(0)=0, u(1)=0 .
\end{array}\right.
$$

For the above equation, the MF is given as follow:

$$
E=\frac{1}{N} \sum_{k=1}^{N}\left(t_{k} \hat{u}^{\prime \prime}\left(t_{k}\right)+\hat{u}^{\prime}\left(t_{k}\right)+t_{k} e^{\hat{u}\left(t_{k}\right)}\right)^{2}+\frac{1}{2}\left(\left(\hat{u}_{0}^{\prime}\right)^{2}+\left(\hat{u}_{N}\right)^{2}\right) .
$$

The exact solution is $2 \ln \left(\frac{4-2 \sqrt{2}}{1+(3-2 \sqrt{2}) t^{2}}\right)$.

To optimize the second kind of LE-NSM based on all problems by functional the GAASM system using the activation GF for independent hundred executions to find the system parameter variables. The set of best weight validates the estimated numerical outcomes for 10 neurons. The mathematical form of the obtained results is given as:

$$
\begin{aligned}
\hat{u}_{1}(t) & =0.7360\left(2 \tan ^{-1} e^{(1.5572 t+0.2711)}-0.5 \pi\right)-1.3828\left(2 \tan ^{-1} e^{(0.0176 t+1.1785)}-0.5 \pi\right)+ \\
& 3.1285\left(2 \tan ^{-1} e^{(-0.320 t-0.1422)}-0.5 \pi\right)-0.5492\left(2 \tan ^{-1} e^{(-0.0149 t-0.104)}-0.5 \pi\right)- \\
& 0.3260\left(2 \tan ^{-1} e^{(-0.261 t-1.2335)}-0.5 \pi\right)-0.8072\left(2 \tan ^{-1} e^{(0.6869 t-0.8473)}-0.5 \pi\right)+ \\
& 1.8626\left(2 \tan ^{-1} e^{(1.0913 t+0.6683)}-0.5 \pi\right)-1.2435\left(2 \tan ^{-1} e^{(1.3372 t-0.1917)}-0.5 \pi\right)- \\
& 0.2982\left(2 \tan ^{-1} e^{(-1.018 t+1.7279)}-0.5 \pi\right)+0.445\left(2 \tan ^{-1} e^{(0.3368 t+0.5995)}-0.5 \pi\right), \\
\hat{u}_{2}(t) & =-5.627\left(2 \tan ^{-1} e^{(4.107 t+13.776)}-0.5 \pi\right)+19.796\left(2 \tan ^{-1} e^{(-1.1441 t+2.700)}-0.5 \pi\right) \\
& -16.9872\left(2 \tan ^{-1} e^{(-1.825 t-5.530)}-0.5 \pi\right)+18.171\left(2 \tan ^{-1} e^{(1.1842 t-2.7152)}-0.5 \pi\right) \\
& -1.1341\left(2 \tan ^{-1} e^{(10.9932 t+17.9253)}-0.5 \pi\right)+9.3739\left(2 \tan ^{-1} e^{(0.2126 t-13.113)}-0.5 \pi\right) \\
& +14.154\left(2 \tan ^{-1} e^{(6.1138 t+17.6261)}-0.5 \pi\right)+8.7317\left(2 \tan ^{-1} e^{(-6.7862 t-16.019)}-0.5 \pi\right) \\
& +5.2472\left(2 \tan ^{-1} e^{(-4.4685 t-6.8103)}-0.5 \pi\right)+1.7752\left(2 \tan ^{-1} e^{(9.4095 t-19.1893)}-0.5 \pi\right), \\
\hat{u}_{2}(t) & =0.7499\left(2 \tan ^{-1} e^{(-0.5392 t+0.7869)}-0.5 \pi\right)+0.435\left(2 \tan ^{-1} e^{(0.2239 t-0.3881)}-0.5 \pi\right) \\
& +1.3708\left(2 \tan ^{-1} e^{(-0.3328 t+0.3684)}-0.5 \pi\right)+0.9967\left(2 \tan ^{-1} e^{(-0.034 t-0.269)}-0.5 \pi\right) \\
& +1.3307\left(2 \tan ^{-1} e^{(0.0317 t-1.9519)}-0.5 \pi\right)-0.2491\left(2 \tan ^{-1} e^{(-1.0871 t-0.2457)}-0.5 \pi\right) \\
& +0.0744\left(2 \tan ^{-1} e^{(0.0144 t-18.028)}-0.5 \pi\right)+2.1415\left(2 \tan ^{-1} e^{(-0.1161 t-0.1017)}-0.5 \pi\right) \\
& -1.6038\left(2 \tan ^{-1} e^{(-0.8301 t-1.3457)}-0.5 \pi\right)+0.0044\left(2 \tan ^{-1} e^{(-0.445 t+0.4301)}-0.5 \pi\right),
\end{aligned}
$$

The best weights set for 10 neurons and comparison of the mean, exact, and the best results for all the problems of the second kind of LE-NSM is shown in Figure 1. The set of best weight is drawn by using Equations 16 to 18. It is seen that the overlapping of the mean, exact, and best results are performed for all the problems of the second kind of LENSM. These results assessment shown in Figure 1 indicates the correctness and exactness of the suggested GNN-GAASM. Figure 2 shows the performance investigations based on the TIC, ENSE, and EVAF operator together with the best, worst, and mean values of AE for all variants of the second kind of LE-NSM. In order to evaluate the performance measures for Problem I, the calculations of the best Fit, ENSE, and EVAF values lie $10^{-10}-10^{-12 \text {, and }}$ the mean values of the Fit, ENSE and EVAF lie $10^{-4}-10^{-6}$. The performance of the best Fit, ENSE, and EVAF values for Problem 2 and 3 lie $10^{-10}-10^{-15}, 10^{-6}-10^{-10}$, and $10^{-7}-10^{-10}$, respectively, while the mean Fit, ENSE, and EVAF are close to $10^{-5}$. In order to measure the absolute error (AE), the best values have been calculated around $10^{-6}$ to $10^{-7}$ for Problem 
I, while for another two problems, the best AE lie $10^{-5}-10^{-6}$. The mean AE values have also been noticed in suitable measures for all variants of the second kind of LE-NSM.
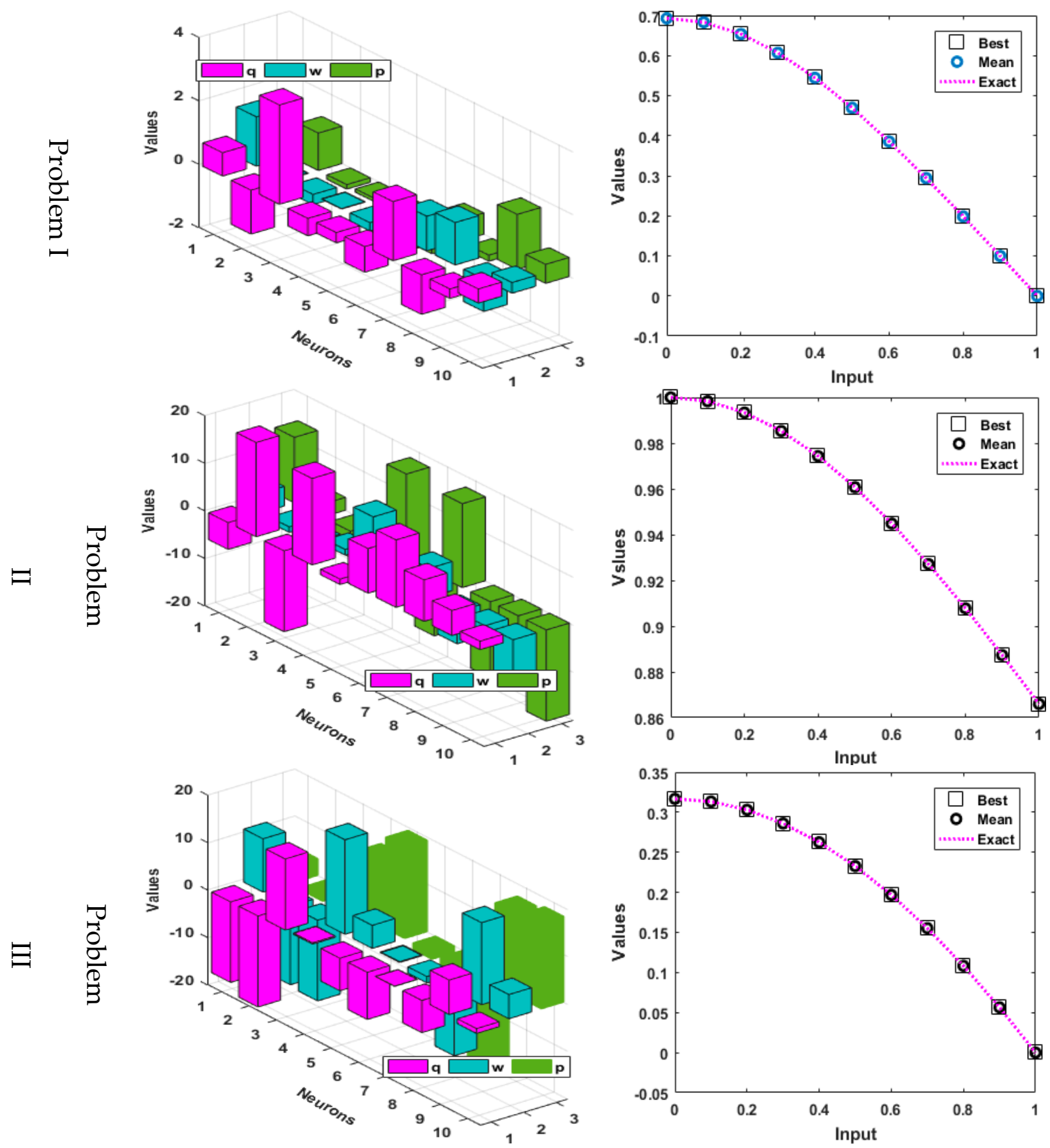

Figure 1. Set of weights for 10 neurons and comparison of the mean, exact and best results for all the problems of the second kind of LE-NSM. 

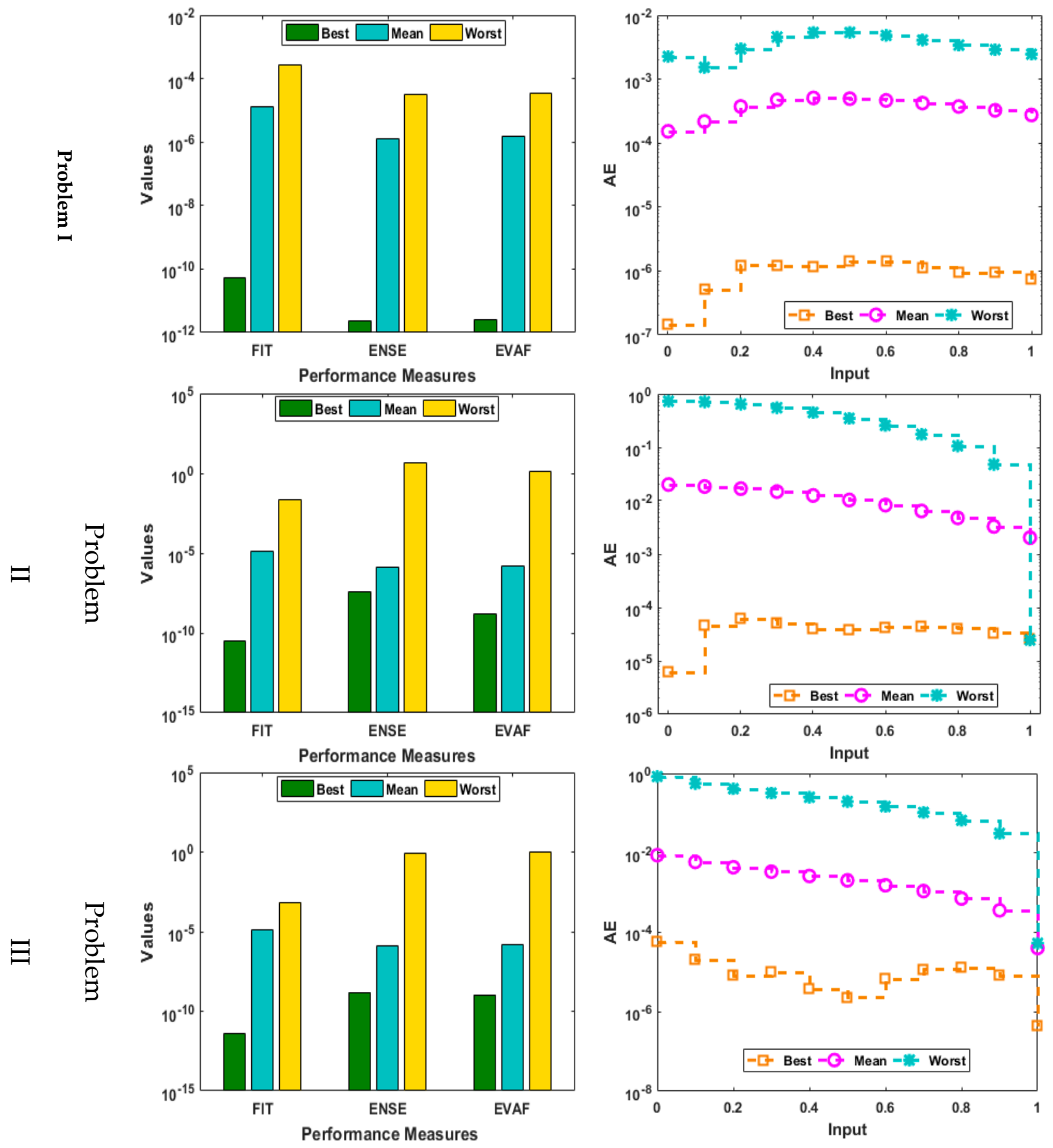

Figure 2. Performance investigations based on the TIC, ENSE, and EVAF operator together with the best, worst, and mean values of AE for all variants of the second kind of LE-NSM.

The plots of the convergence measures for the Fit, ENSE, and EVAF together with the boxplots and histogram are given in Figures 3-5 for for all variants of the second kind of LE-NSM. It is indicated that most of the Fit, EVAF, and ENSE values for all the problems lie around $10^{-5}$ to $10^{-10}, 10^{-6}$ to $10^{-9}$, and $10^{-7}$ to $10^{-9}$, respectively. One can determine that the accurate, precise, and specific values of the ENSE and EVAF operators have been obtained for all variants of the second kind of LE-NSM. 


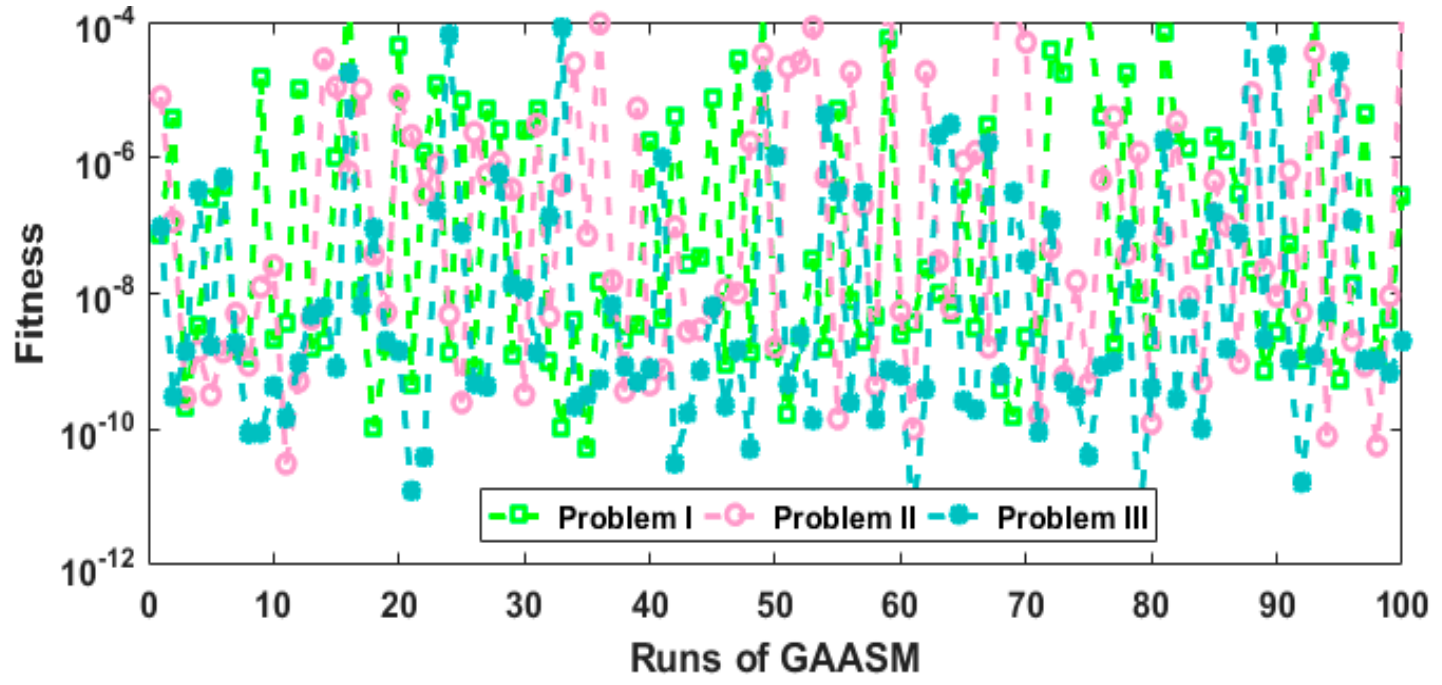

(a) Fit values in convergence studies for Problems-III
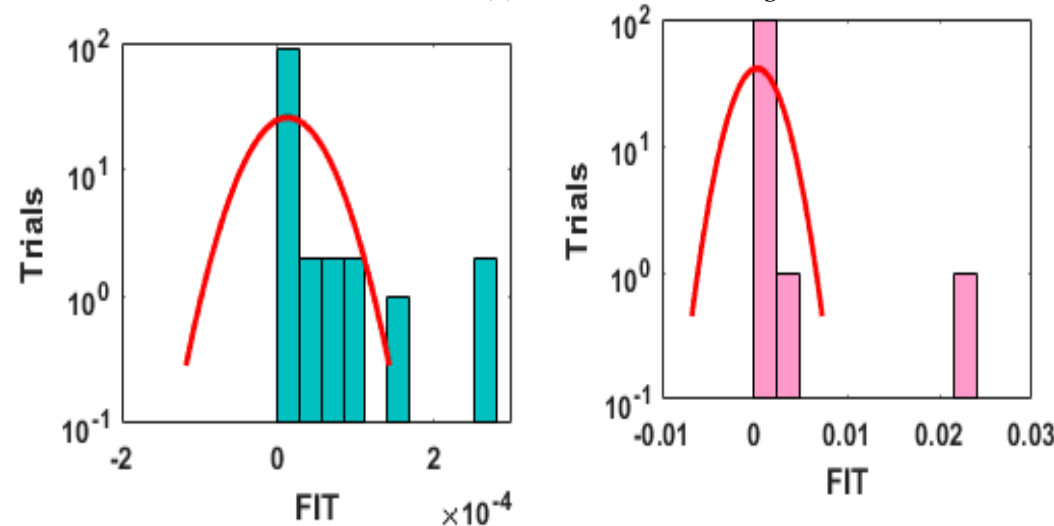

(b) HistforProblem I

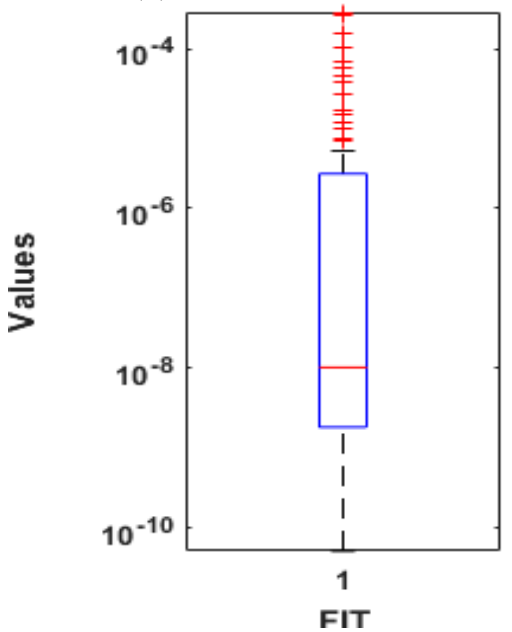

(e) Boxplot for Problem I (c) Hist for Problem II

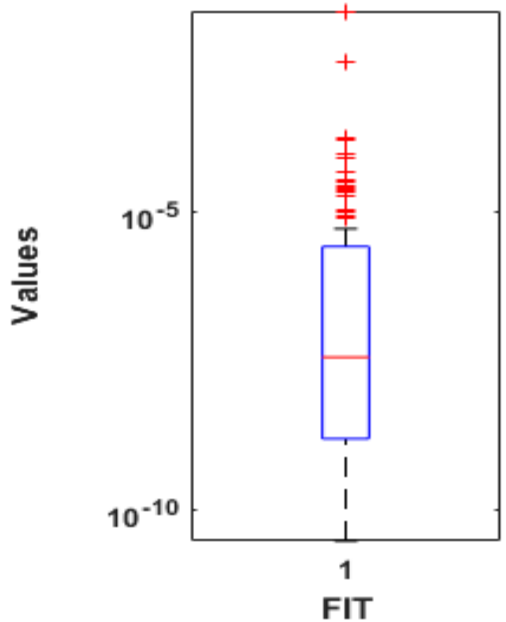

(f) Boxplot for Problem II

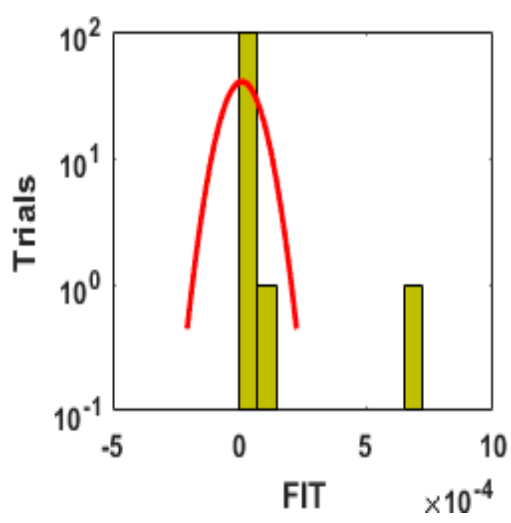

(d) Histogram values for Problem III

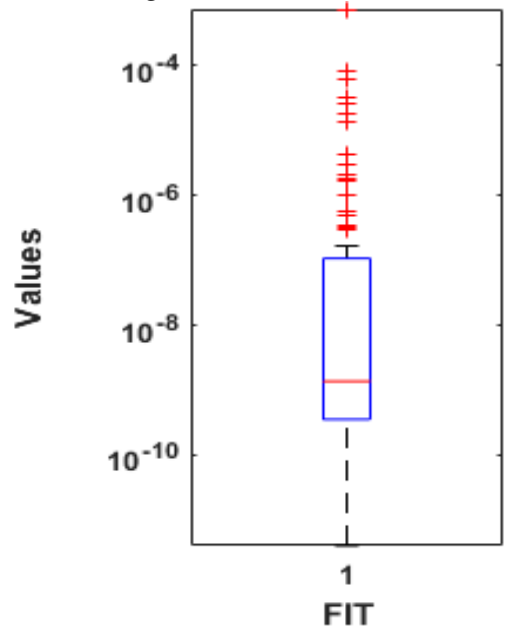

(g) Boxplot for Problem III

Figure 3. Statistical studies through Fitness, histogram together with boxplots for all variants of the second kind of LE-NSM. 


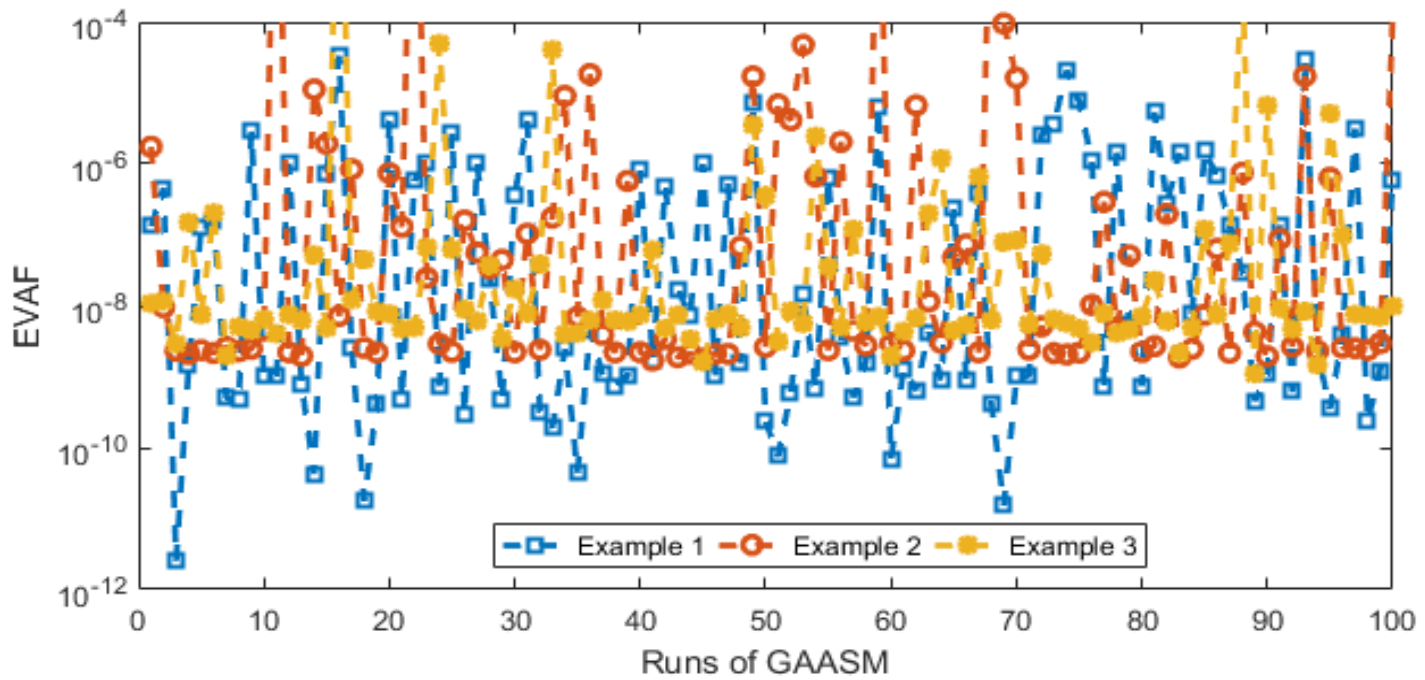

(a) EVAF values in convergence studies for Problems I-III

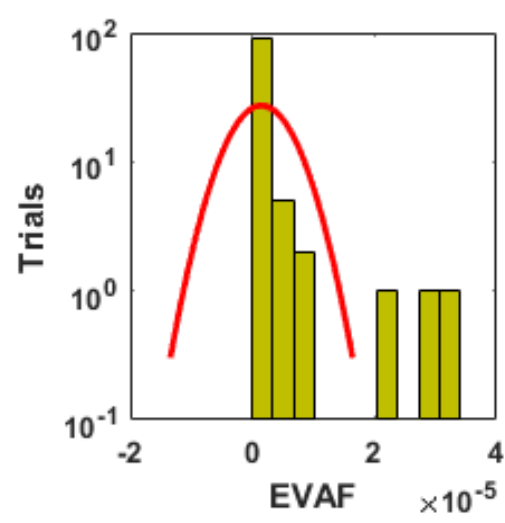

(b) Histfor Problem I

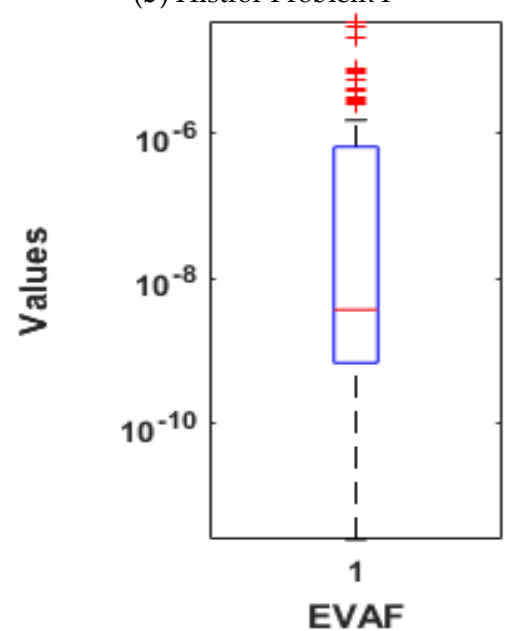

(e) Boxplot for Problem I

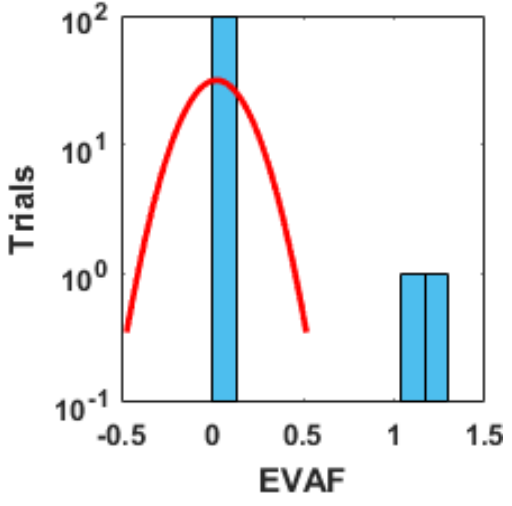

(c) Hist for Problem II

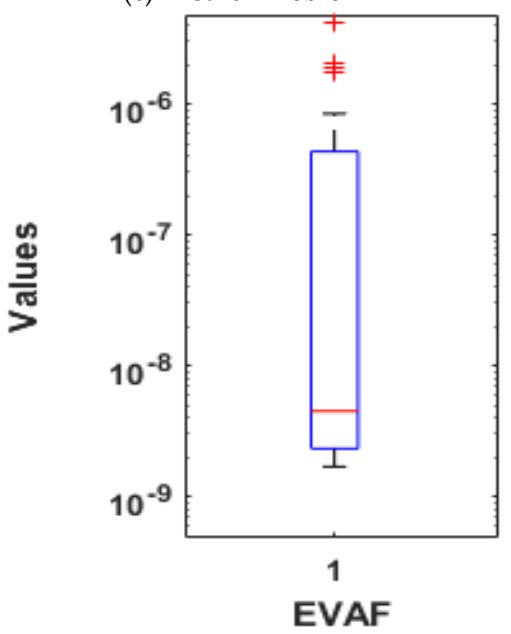

(f) Boxplot for Problem II

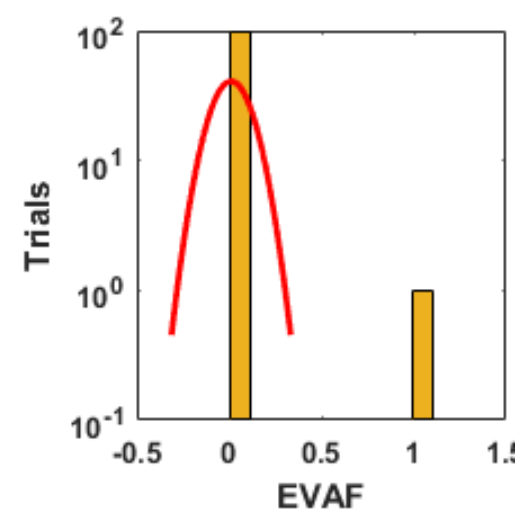

(d) Histogram values for Problem III

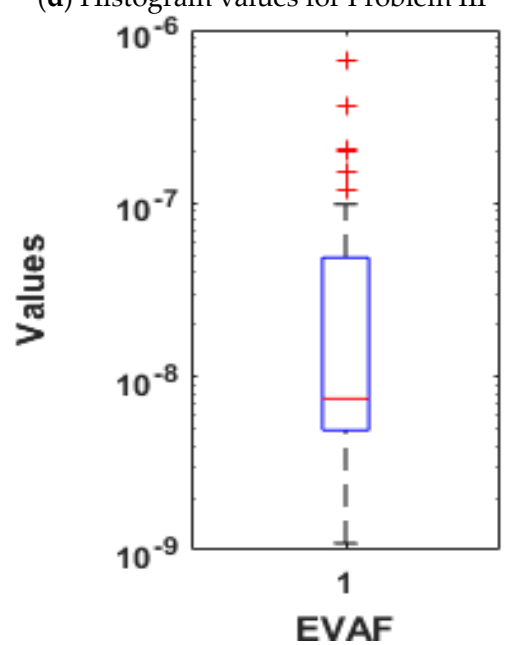

(g) Boxplot for Problem III

Figure 4. Statistical studies through EVAF, histogram together with boxplots for all variants of the second kind of LE-NSM. 


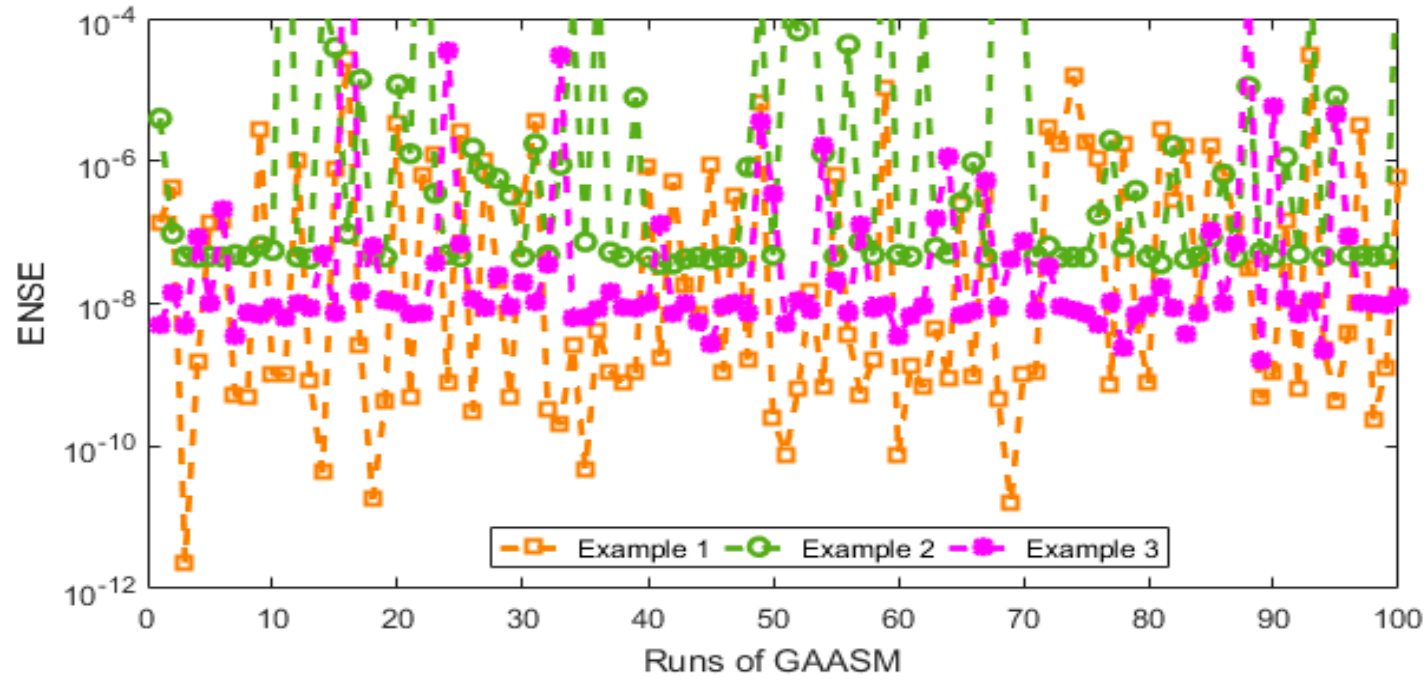

(a) ENSE values in convergence studies for Problems I-III
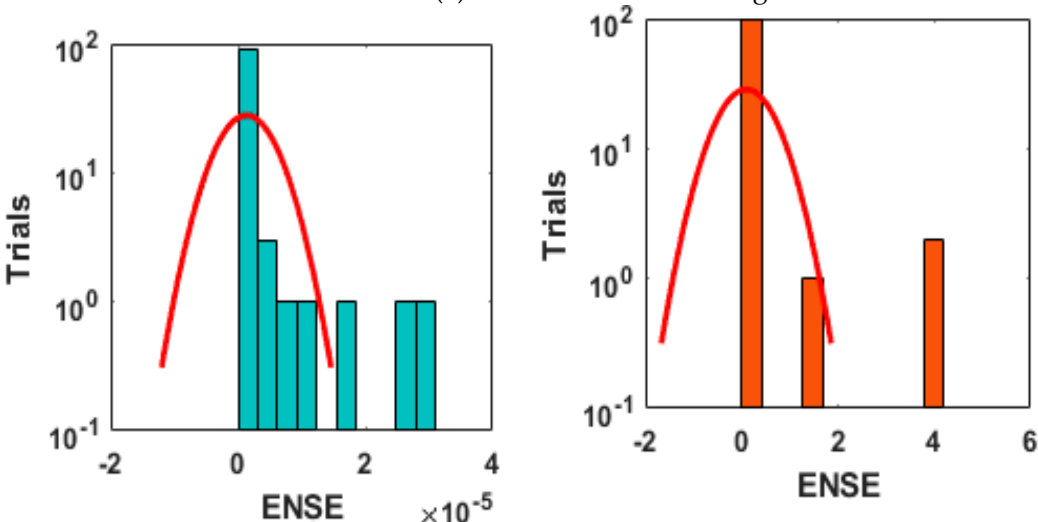

(b) Hist for Problem I

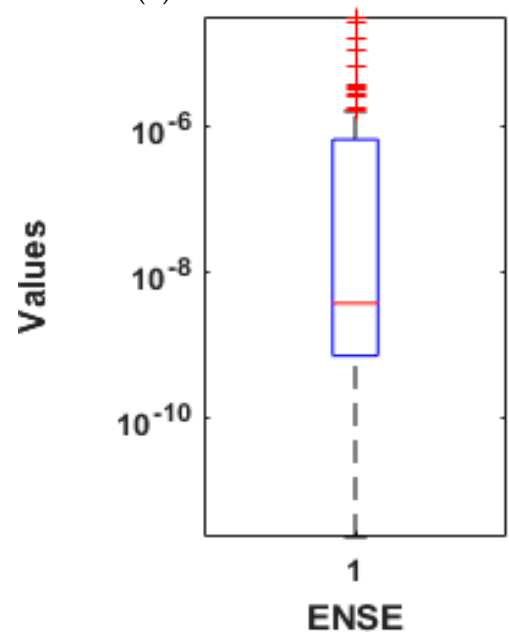

(e) Boxplot for Problem I

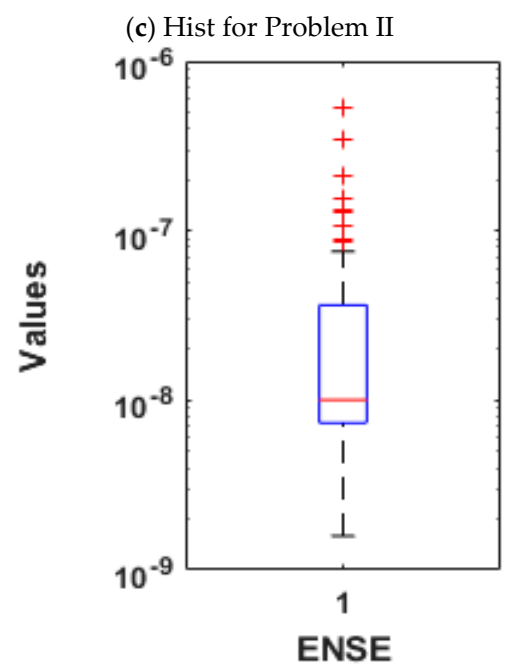

(f) Boxplot for Problem II

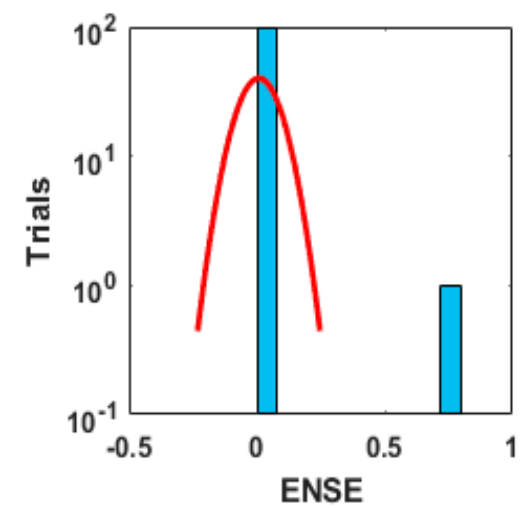

(d) Histogram values for Problem III

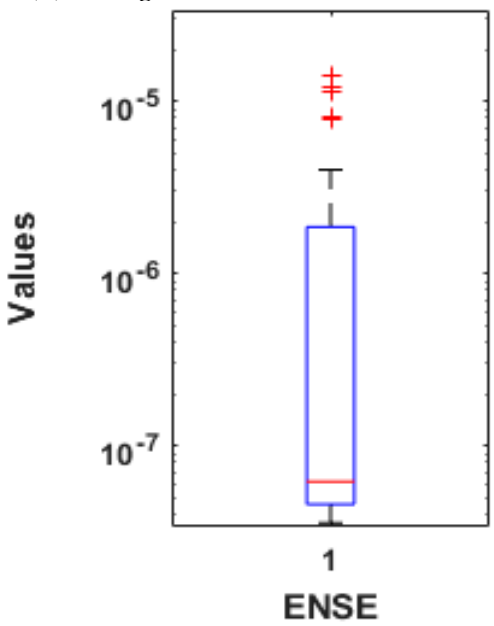

(g) Boxplot for Problem III

Figure 5. Statistical studies through EVAF, histogram together with boxplots for all variants of the second kind of LE-NSM.

The statistical presentations have been examined using the GNN-GAASM to solve all variants of the second kind of LE-NSM for 100 executions based on the maximum (Max), minimum (Min), semi-interquartile range (S.I.R), median (MED), mean, and standard deviation (STD). The Min values show the best outcomes, while Max values are calculated based on worst runs using the GNN-GAASM are given in Table 2. The mathematical form of the S.I.R is one-half of the difference between the third and first quartiles, respectively. These statistics-based performances for all variants of the second kind of LE-NSM are found 
to be satisfactory and endorse the precision/accuracy of the proposed GNN-GAASM. The global demonstrations for all the variants of the second kind of LE-NSM using the proposed GNN-GAASM are given in Table 3. [G.FIT], [G.EVAF] and [G.ENSE] based Min values lie in the ranges of $10^{-11}-10^{-12}, 10^{-9}-10^{-12}$, and $10^{-8}-10^{-9}$, respectively, while the MEDbased values for all the operators are examined around $10^{-8}$ to $10^{-9}$ for the second kind of LE-NSM using GNN-GAASM. These optimum obtained values from the mentioned statistical performances based on global operators authorize the accuracy of the GNNGAASM. The convergence measures for all variants of the second kind of LE-NSM using GNN-GAASM are given in Table 4. The complexity analysis for the designed second kind of LE-NSM using GNN-GAASM using the generation, implemented time, and function calculations are given in Table 5. It is concluded that the average generations, implemented time together with the function calculations are around 39.1709, 383.0966, and 29,623.3967, respectively, for the second kind of LE-NSM using GNN-GAASM.

Table 2. Statistical performances for all variants of the second kind of LE-NSM.

\begin{tabular}{|c|c|c|c|c|c|c|c|c|c|c|c|c|}
\hline \multirow{2}{*}{ Index } & \multirow{2}{*}{ Gages } & \multicolumn{11}{|c|}{ The Projected GNN-GAASM Outcomes of the Second Kind of LE-NSM } \\
\hline & & 0 & 0.10 & 0.20 & 0.30 & 0.40 & 0.50 & 0.60 & 0.70 & 0.80 & 0.90 & 1.0 \\
\hline \multirow{6}{*}{ P I } & Min & $1 \times 10^{-7}$ & $5 \times 10^{-7}$ & $7 \times 10^{-7}$ & $1 \times 10^{-6}$ & $1 \times 10^{-6}$ & $1 \times 10^{-6}$ & $1 \times 10^{-6}$ & $1 \times 10^{-6}$ & $9 \times 10^{-7}$ & $9 \times 10^{-7}$ & $7 \times 10^{-7}$ \\
\hline & Med & $5 \times 10^{-6}$ & $2 \times 10^{-5}$ & $4 \times 10^{-5}$ & $5 \times 10^{-5}$ & $5 \times 10^{-5}$ & $5 \times 10^{-5}$ & $5 \times 10^{-5}$ & $4 \times 10^{-5}$ & $3 \times 10^{-5}$ & $3 \times 10^{-5}$ & $2 \times 10^{-5}$ \\
\hline & Max & $2 \times 10^{-3}$ & $1 \times 10^{-3}$ & $3 \times 10^{-3}$ & $4 \times 10^{-3}$ & $5 \times 10^{-3}$ & $5 \times 10^{-3}$ & $4 \times 10^{-3}$ & $4 \times 10^{-3}$ & $3 \times 10^{-3}$ & $2 \times 10^{-3}$ & $2 \times 10^{-3}$ \\
\hline & Mean & $1 \times 10^{-4}$ & $2 \times 10^{-4}$ & $3 \times 10^{-4}$ & $4 \times 10^{-4}$ & $5 \times 10^{-4}$ & $5 \times 10^{-4}$ & $4 \times 10^{-4}$ & $4 \times 10^{-4}$ & $3 \times 10^{-4}$ & $3 \times 10^{-4}$ & $2 \times 10^{-4}$ \\
\hline & S.I.R & $4 \times 10^{-5}$ & $1 \times 10^{-4}$ & $2 \times 10^{-4}$ & $3 \times 10^{-4}$ & $3 \times 10^{-4}$ & $3 \times 10^{-4}$ & $3 \times 10^{-4}$ & $3 \times 10^{-4}$ & $2 \times 10^{-4}$ & $2 \times 10^{-4}$ & $1 \times 10^{-4}$ \\
\hline & STD & $4 \times 10^{-4}$ & $3 \times 10^{-4}$ & $5 \times 10^{-4}$ & $8 \times 10^{-4}$ & $9 \times 10^{-4}$ & $9 \times 10^{-4}$ & $8 \times 10^{-4}$ & $7 \times 10^{-4}$ & $6 \times 10^{-4}$ & $5 \times 10^{-4}$ & $4 \times 10^{-4}$ \\
\hline \multirow{5}{*}{ P II } & Min & $1 \times 10^{-7}$ & $5 \times 10^{-7}$ & $7 \times 10^{-7}$ & $1 \times 10^{-6}$ & $1 \times 10^{-6}$ & $1 \times 10^{-6}$ & $1 \times 10^{-6}$ & $1 \times 10^{-6}$ & $9 \times 10^{-7}$ & $9 \times 10^{-7}$ & $7 \times 10^{-7}$ \\
\hline & Med & $5 \times 10^{-6}$ & $2 \times 10^{-5}$ & $4 \times 10^{-5}$ & $5 \times 10^{-5}$ & $5 \times 10^{-5}$ & $5 \times 10^{-5}$ & $5 \times 10^{-5}$ & $4 \times 10^{-5}$ & $3 \times 10^{-5}$ & $3 \times 10^{-5}$ & $2 \times 10^{-5}$ \\
\hline & Max & $2 \times 10^{-3}$ & $1 \times 10^{-3}$ & $3 \times 10^{-3}$ & $4 \times 10^{-3}$ & $5 \times 10^{-3}$ & $5 \times 10^{-3}$ & $4 \times 10^{-3}$ & $4 \times 10^{-3}$ & $3 \times 10^{-3}$ & $2 \times 10^{-3}$ & $2 \times 10^{-3}$ \\
\hline & Mean & $1 \times 10^{-4}$ & $2 \times 10^{-4}$ & $3 \times 10^{-4}$ & $4 \times 10^{-4}$ & $5 \times 10^{-4}$ & $5 \times 10^{-4}$ & $4 \times 10^{-4}$ & $4 \times 10^{-4}$ & $3 \times 10^{-4}$ & $3 \times 10^{-4}$ & $2 \times 10^{-4}$ \\
\hline & S.I.R & $4 \times 10^{-5}$ & $1 \times 10^{-4}$ & $2 \times 10^{-4}$ & $3 \times 10^{-4}$ & $3 \times 10^{-4}$ & $3 \times 10^{-4}$ & $3 \times 10^{-4}$ & $3 \times 10^{-4}$ & $2 \times 10^{-4}$ & $2 \times 10^{-4}$ & $1 \times 10^{-4}$ \\
\hline \multirow{7}{*}{ P III } & STD & $4 \times 10^{-4}$ & $3 \times 10^{-4}$ & $5 \times 10^{-4}$ & $8 \times 10^{-4}$ & $9 \times 10^{-4}$ & $9 \times 10^{-4}$ & $8 \times 10^{-4}$ & $7 \times 10^{-4}$ & $6 \times 10^{-4}$ & $5 \times 10^{-4}$ & $4 \times 10^{-4}$ \\
\hline & Min & $1 \times 10^{-7}$ & $5 \times 10^{-7}$ & $7 \times 10^{-7}$ & $1 \times 10^{-6}$ & $1 \times 10^{-6}$ & $1 \times 10^{-6}$ & $1 \times 10^{-6}$ & $1 \times 10^{-6}$ & $9 \times 10^{-7}$ & $9 \times 10^{-7}$ & $7 \times 10^{-7}$ \\
\hline & Med & $5 \times 10^{-6}$ & $2 \times 10^{-5}$ & $4 \times 10^{-5}$ & $5 \times 10^{-5}$ & $5 \times 10^{-5}$ & $5 \times 10^{-5}$ & $5 \times 10^{-5}$ & $4 \times 10^{-5}$ & $3 \times 10^{-5}$ & $3 \times 10^{-5}$ & $2 \times 10^{-5}$ \\
\hline & Max & $2 \times 10^{-3}$ & $1 \times 10^{-3}$ & $3 \times 10^{-3}$ & $4 \times 10^{-3}$ & $5 \times 10^{-3}$ & $5 \times 10^{-3}$ & $4 \times 10^{-3}$ & $4 \times 10^{-3}$ & $3 \times 10^{-3}$ & $2 \times 10^{-3}$ & $2 \times 10^{-3}$ \\
\hline & Mean & $1 \times 10^{-4}$ & $2 \times 10^{-4}$ & $3 \times 10^{-4}$ & $4 \times 10^{-4}$ & $5 \times 10^{-4}$ & $5 \times 10^{-4}$ & $4 \times 10^{-4}$ & $4 \times 10^{-4}$ & $3 \times 10^{-4}$ & $3 \times 10^{-4}$ & $2 \times 10^{-4}$ \\
\hline & S.I.R & $4 \times 10^{-5}$ & $1 \times 10^{-4}$ & $2 \times 10^{-4}$ & $3 \times 10^{-4}$ & $3 \times 10^{-4}$ & $3 \times 10^{-4}$ & $3 \times 10^{-4}$ & $3 \times 10^{-4}$ & $2 \times 10^{-4}$ & $2 \times 10^{-4}$ & $1 \times 10^{-4}$ \\
\hline & STD & $4 \times 10^{-4}$ & $3 \times 10^{-4}$ & $5 \times 10^{-4}$ & $8 \times 10^{-4}$ & $9 \times 10^{-4}$ & $9 \times 10^{-4}$ & $8 \times 10^{-4}$ & $7 \times 10^{-4}$ & $6 \times 10^{-4}$ & $5 \times 10^{-4}$ & $4 \times 10^{-4}$ \\
\hline
\end{tabular}

Table 3. Global demonstrations for all variants of the second kind of LE-NSM using the GNN-GAASM.

\begin{tabular}{|c|c|c|c|c|c|c|}
\hline \multirow{2}{*}{ Problem } & \multicolumn{2}{|c|}{ [G.FIT] } & \multicolumn{2}{|c|}{ [G.EVAF] } & \multicolumn{2}{|c|}{ [G.ENSE] } \\
\hline & Min & MED & Min & MED & Min & MED \\
\hline 1 & $5.227610 \times 10^{-11}$ & $1.028782 \times 10^{-8}$ & $2.535194 \times 10^{-12}$ & $3.717371 \times 10^{-9}$ & $2.312817 \times 10^{-12}$ & $3.756261 \times 10^{-9}$ \\
\hline 2 & $3.099837 \times 10^{-11}$ & $3.760316 \times 10^{-8}$ & $1.690676 \times 10^{-9}$ & $4.479814 \times 10^{-9}$ & $3.557807 \times 10^{-8}$ & $6.170927 \times 10^{-8}$ \\
\hline 3 & $3.994743 \times 10^{-12}$ & $1.372601 \times 10^{-9}$ & $1.096359 \times 10^{-9}$ & $7.456837 \times 10^{-9}$ & $1.590472 \times 10^{-9}$ & $1.006110 \times 10^{-8}$ \\
\hline
\end{tabular}

Table 4. Convergence measures for all variants of the second kind of LE-NSM using the GNNGAASM.

\begin{tabular}{cccccccccc}
\hline \multirow{2}{*}{ Problem } & \multicolumn{3}{c}{ FIT $\leq$} & \multicolumn{3}{c}{ EVAF $\leq$} & \multicolumn{3}{c}{ ENSE $\leq$} \\
\cline { 2 - 10 } & $\mathbf{1 0}^{-\mathbf{4}}$ & $\mathbf{1 0}^{-\mathbf{5}}$ & $\mathbf{1 0}^{-\mathbf{6}}$ & $\mathbf{1 0}^{-\mathbf{4}}$ & $\mathbf{1 0}^{-\mathbf{5}}$ & $\mathbf{1 0}^{-\mathbf{6}}$ & $\mathbf{1 0}^{-\mathbf{7}}$ & $\mathbf{1 0}^{-\mathbf{8}}$ & $\mathbf{1 0}^{-\mathbf{9}}$ \\
\hline I & 100 & 93 & 81 & 100 & 100 & 72 & 100 & 100 & 100 \\
II & 98 & 93 & 78 & 97 & 93 & 77 & 100 & 100 & 100 \\
III & 99 & 97 & 93 & 99 & 99 & 93 & 100 & 100 & 100 \\
\hline
\end{tabular}


Table 5. Complexity presentations for all variants of the second kind of LE-NSM using the GNN-GAASM.

\begin{tabular}{ccccccc}
\hline \multirow{2}{*}{ Problem } & \multicolumn{2}{c}{ Iterations } & \multicolumn{2}{c}{ Implemented Time } & \multicolumn{2}{c}{ Function Computations } \\
\cline { 2 - 7 } & Mean & STD & Mean & STD & Mean & STD \\
\hline I & 28.42678858 & 7.64904008 & 396.38000000 & 136.03213970 & $30,490.24000000$ & 8905.29769705 \\
II & 73.21185177 & 583.79311938 & 366.69000000 & 156.81486833 & $28,517.91000000$ & 9840.05489852 \\
III & 15.87415954 & 5.49982366 & 386.22000000 & 143.77371249 & $29,862.04000000$ & 9239.89403599 \\
\hline
\end{tabular}

\section{Conclusions}

The current research work is related to design a novel Gudermannian neural network for solving the nonlinear Lane-Emden singular model of the second kind using GNNGAASM containing the singular point at the origin using 10 neurons. The optimization is produced by the global skill of genetic algorithms and rapid modification of applicant solutions by working the local search through the active-set scheme. The solver based on Gudermannian computing intelligent neural network is designed with the layer structure neural network models for solving the second kind of nonlinear Lane-Emden singular model. The precision, convergence, and accuracy of the stochastic numerical solver are anticipated to attain the matching/overlapping results with the exact solutions having 6 to 8 decimal levels of accuracy for the second kind of nonlinear Lane-Emden singular model. Furthermore, statistical interpretations based on 100 executions for the second kind of nonlinear Lane-Emden singular model, in the form of maximum, minimum, median, mean, standard deviation, and semi-interquartile range, validate the trustworthiness, exactness, robustness, and correctness of the proposed GNN-GAASM that is specified further by the procedures of ENSE and EVAF.

In the future, the designed ANN-PSOIPA can be functional to apply to the biological models $[58,59]$ and fluid dynamics models [60-63].

Author Contributions: K.N.; Resource and review, Z.S. Writing-up and Software, M.A.Z.R.; Review and Edit, Methodology, A.A.A.I., Resources, J.J.P.C.R.; Supervision, A.S.K.; Administrations, M.G.; Validation, A.K.; Project Supervision, and D.B.R.; Conceptulization. All authors have read and agreed to the published version of the manuscript.

Funding: This work was supported in part by the APC funded by Universiti Malaysia Sabah, Jalan UMS, 88400, KK, Malaysia. This work is partially supported by FCT/MCTES through national funds and when applicable co-funded EU funds under the Project UIDB/50008/2020; and by Brazilian National Council for Scientific and Technological Development - CNPq, via Grant No. 313036/2020-9.

Institutional Review Board Statement: Not Applicable.

Informed Consent Statement: Not Applicable.

Data Availability Statement: Not Applicable.

Conflicts of Interest: The authors describe that they have no conflict of interest.

\section{References}

1. Lane, H.J. On the Theoretical Temperature of the Sun, under the Hypothesis of a gaseous Mass maintaining its Volume by its internal Heat and depending on the laws of gases as known to terrestrial Experiment. Am. J. Sci. 1870, 148, 57-74. [CrossRef]

2. Emden, R. Gaskugeln Teubner; Scientific Research: Leipzig und Berlin, Germany, 1907.

3. Ahmad, I.; Raja, M.A.Z.; Bilal, M.; Ashraf, F. Neural network methods to solve the Lane-Emden type equations arising in thermodynamic studies of the spherical gas cloud model. Neural Comput. Appl. 2017, 28, 929-944. [CrossRef]

4. Sabir, Z.; Wahab, H.A.; Umar, M.; Sakar, M.G.; Raja, M.A.Z. Novel design of Morlet wavelet neural network for solving second order Lane-Emden equation. Math. Comput. Simul. 2020, 172, 1-14. [CrossRef]

5. Luo, T.; Xin, Z.; Zeng, H. Nonlinear asymptotic stability of the Lane-Emden solutions for the viscous gaseous star problem with degenerate density dependent viscosities. Commun. Math. Phys. 2016, 347, 657-702. [CrossRef]

6. Baleanu, D.; Sajjadi, S.S.; Jajarmi, A.; Asad, J.H. New features of the fractional Euler-Lagrange equations for a physical system within non-singular derivative operator. Eur. Phys. J. Plus 2019, 134, 181. [CrossRef] 
7. Khan, J.A.; Raja, M.A.Z.; Rashidi, M.M.; Syam, M.I.; Wazwaz, A.M. Nature-inspired computing approach for solving non-linear singular Emden-Fowler problem arising in electromagnetic theory. Connect. Sci. 2015, 27, 377-396. [CrossRef]

8. Rach, R.; Duan, J.S.; Wazwaz, A.M. Solving coupled Lane-Emden boundary value problems in catalytic diffusion reactions by the Adomian decomposition method. J. Math. Chem. 2014, 52, 255-267. [CrossRef]

9. Ghergu, M.; Rădulescu, V. On a class of singular Gierer-Meinhardt systems arising in morphogenesis. Comptes Rendus Math. 2007, 344, 163-168. [CrossRef]

10. Bhrawy, A.H.; Alofi, A.S.; Van Gorder, R.A. An efficient collocation method for a class of boundary value problems arising in mathematical physics and geometry. In Abstract and Applied Analysis; Hindawi Publishing Corporation: Orlando, FL, USA, 2014; Volume 2014.

11. Dehghan, M.; Shakeri, F. Solution of an Integro-Differential Equation Arising in Oscillating Magnetic Fields Using He's Homotopy Perturbation Method. Prog. Electromagn. Res. 2008, 78, 361-376. [CrossRef]

12. Radulescu, V.; Repovš, D. Combined effects in nonlinear problems arising in the study of anisotropic continuous media. Nonlinear Anal. Theory Methods Appl. 2012, 75, 1524-1530. [CrossRef]

13. Flockerzi, D.; Sundmacher, K. On coupled Lane-Emden equations arising in dusty fluid models. J. Phys. Conf. Ser. 2011, 268, 012006. [CrossRef]

14. Adel, W.; Sabir, Z. Solving a new design of nonlinear second-order Lane-Emden pantograph delay differential model via Bernoulli collocation method. Eur. Phys. J. Plus 2020, 135, 427. [CrossRef]

15. Liao, S. A new analytic algorithm of Lane-Emden type equations. Appl. Math. Comput. 2003, 142, 1-16. [CrossRef]

16. Mandelzweig, V.B.; Tabakin, F. Quasilinearization approach to nonlinear problems in physics with application to nonlinear ODEs. Comput. Phys. Commun. 2001, 141, 268-281. [CrossRef]

17. Sabir, Z.; Umar, M.; Guirao, J.L.; Shoaib, M.; Raja, M.A.Z. Integrated intelligent computing paradigm for nonlinear multi-singular third-order Emden-Fowler equation. Neural Comput. Appl. 2021, 33, 3417-3436. [CrossRef]

18. Zhang, H.; Qing, H. Cooperative bat searching algorithm: A combined perspective from multiagent coordination and swarm intelligence. In Proceedings of the 2017 13th IEEE Conference on Automation Science and Engineering (CASE), Xi'an, China, 20-23 August 2017.

19. Sabir, Z.; Saoud, S.; Raja, M.A.Z.; Wahab, H.A.; Arbi, A. Heuristic computing technique for numerical solutions of nonlinear fourth order Emden-Fowler equation. Math. Comput. Simul. 2020, 178, 534-548. [CrossRef]

20. Raja, M.A.Z.; Mehmood, J.; Sabir, Z.; Nasab, A.K.; Manzar, M.A. Numerical solution of doubly singular nonlinear systems using neural networks-based integrated intelligent computing. Neural Comput. Appl. 2019, 31, 793-812. [CrossRef]

21. Ahmad, I.; Ilyas, H.; Urooj, A.; Aslam, M.S.; Shoaib, M.; Raja, M.A.Z. Novel applications of intelligent computing paradigms for the analysis of nonlinear reactive transport model of the fluid in soft tissues and microvessels. Neural Comput. Appl. 2019, 31, 9041-9059. [CrossRef]

22. Ahmad, S.I.; Faisal, F.; Shoaib, M.; Raja, M.A.Z. A new heuristic computational solver for nonlinear singular Thomas-Fermi system using evolutionary optimized cubic splines. Eur. Phys. J. Plus 2020, 135, 1-29. [CrossRef]

23. Sabir, Z.; Raja, M.A.Z.; Umar, M.; Shoaib, M. Design of neuro-swarming-based heuristics to solve the third-order nonlinear multi-singular Emden-Fowler equation. Eur. Phys. J. Plus 2020, 135, 410. [CrossRef]

24. Raja, M.A.Z.; Ahmed, T.; Shah, S.M. Intelligent computing strategy to analyze the dynamics of convective heat transfer in MHD slip flow over stretching surface involving carbon nanotubes. J. Taiwan Inst. Chem. Eng. 2017, 80, 935-953. [CrossRef]

25. Bukhari, A.H.; Sulaiman, M.; Raja, M.A.Z.; Islam, S.; Shoaib, M.; Kumam, P. Design of a hybrid NAR-RBFs neural network for nonlinear dusty plasma system. Alex. Eng. J. 2020, 59, 3325-3345. [CrossRef]

26. Umar, M.; Raja, M.A.Z.; Sabir, Z.; Alwabli, A.S.; Shoaib, M. A stochastic computational intelligent solver for numerical treatment of mosquito dispersal model in a heterogeneous environment. Eur. Phys. J. Plus 2020, 135, 1-23. [CrossRef]

27. Abo-Hammour, Z.S.; Samhouri, A.D.; Mubarak, Y. Continuous Genetic Algorithm as a Novel Solver for Stokes and Nonlinear Navier Stokes Problems. Math. Probl. Eng. 2014, 2014, 649630. [CrossRef]

28. Sabir, Z.; Raja, M.A.Z.; Umar, M.; Shoaib, M. Neuro-swarm intelligent computing to solve the second-order singular functional differential model. Eur. Phys. J. Plus 2020, 135, 474. [CrossRef]

29. Umar, M.; Sabir, Z.; Amin, F.; Guirao, J.L.; Raja, M.A.Z. Stochastic numerical technique for solving HIV infection model of CD4+ T cells. Eur. Phys. J. Plus 2020, 135, 403. [CrossRef]

30. Raja, M.A.Z.; Shah, F.H.; Tariq, M.; Ahmad, I. Design of artificial neural network models optimized with sequential quadratic programming to study the dynamics of nonlinear Troesch's problem arising in plasma physics. Neural Comput. Appl. 2016, 29, 83-109. [CrossRef]

31. Sabir, Z.; Manzar, M.A.; Raja, M.A.Z. Neuro-heuristics for nonlinear singular Thomas-Fermi systems. Appl. Soft Comput. 2018, 65, 152-169. [CrossRef]

32. Umar, M.; Sabir, Z.; Raja, M.A.Z. Intelligent computing for numerical treatment of nonlinear prey-predator models. Appl. Soft Comput. 2019, 80, 506-524. [CrossRef]

33. Raja, M.A.Z.; Farooq, U.; Chaudhary, N.I.; Wazwaz, A.M. Stochastic numerical solver for nanofluidic problems containing multi-walled carbon nanotubes. Appl. Soft Comput. 2016, 38, 561-586. [CrossRef]

34. Liang, H.; Wei, Q.; Lu, D.; Li, Z. Application of GA-BP neural network algorithm in killing well control system. Neural Comput. Appl. 2021, 33, 949-960. [CrossRef] 
35. Umar, M.; Amin, F.; Wahab, H.A.; Baleanu, D. Unsupervised constrained neural network modeling of boundary value corneal model for eye surgery. Appl. Soft Comput. 2019, 85, 105826. [CrossRef]

36. Mehmood, A.; Zameer, A.; Ling, S.H.; Raja, M.A.Z. Design of neuro-computing paradigms for nonlinear nanofluidic systems of MHD Jeffery-Hamel flow. J. Taiwan Inst. Chem. Eng. 2018, 91, 57-85. [CrossRef]

37. Baghban, A.; Kardani, M.N.; Mohammadi, A.H. Improved estimation of Cetane number of fatty acid methyl esters (FAMEs) based biodiesels using TLBO-NN and PSO-NN models. Fuel 2018, 232, 620-631. [CrossRef]

38. Mitchell, M.; Holland, J.H.; Forrest, S. Relative Building-Block Fitness and the Building Block Hypothesis. In Foundations of Genetic Algorithms; D. Whitley: Aizu-Wakamatsu City, Japan, 2014; Volume 2, pp. 109-126.

39. Lee, J.-C.; Lin, W.-M.; Liao, G.-C.; Tsao, T.-P. Quantum genetic algorithm for dynamic economic dispatch with valve-point effects and including wind power system. Int. J. Electr. Power Energy Syst. 2011, 33, 189-197. [CrossRef]

40. Anbarasi, M.; Anupriya, E.; Iyengar, N.C.S.N. Enhanced prediction of heart disease with feature subset selection using genetic algorithm. Int. J. Eng. Sci. Technol. 2010, 2, 5370-5376.

41. Raja, M.A.Z.; Umar, M.; Sabir, Z.; Khan, J.A.; Baleanu, D. A new stochastic computing paradigm for the dynamics of nonlinear singular heat conduction model of the human head. Eur. Phys. J. Plus 2018, 133, 364. [CrossRef]

42. Arabali, A.; Ghofrani, M.B.; Etezadi-Amoli, M.; Fadali, M.S.; Baghzouz, Y. Genetic-Algorithm-Based Optimization Approach for Energy Management. IEEE Trans. Power Deliv. 2013, 28, 162-170. [CrossRef]

43. Chung, Y.G.; Gómez-Gualdrón, D.A.; Li, P.; Leperi, K.T.; Deria, P.; Zhang, H.; Vermeulen, N.A.; Stoddart, J.F.; You, F.; Hupp, J.T.; et al. In silico discovery of metal-organic frameworks for precombustion CO2 capture using a genetic algorithm. Sci. Adv. 2016, 2, e1600909. [CrossRef]

44. Gai, K.; Qiu, M.; Zhao, H. Cost-aware multimedia data allocation for heterogeneous memory using genetic algorithm in cloud computing. IEEE Trans. Cloud Comput. 2017. [CrossRef]

45. Raja, M.A.Z.; Shah, F.H.; Alaidarous, E.S.; Syam, M.I. Design of bio-inspired heuristic technique integrated with interior-point algorithm to analyze the dynamics of heartbeat model. Appl. Soft Comput. 2017, 52, 605-629. [CrossRef]

46. Ball, M.G.; Qela, B.; Wesolkowski, S. A Review of the Use of Computational Intelligence in the Design of Military Surveillance Networks. In Complex Networks \& Their Applications IX.; Springer International Publishing: Berlin/Heidelberg, Germany, 2015; pp. 663-693. [CrossRef]

47. Jacob, S.; Banerjee, R. Modeling and optimization of anaerobic codigestion of potato waste and aquatic weed by response surface methodology and artificial neural network coupled genetic algorithm. Bioresour. Technol. 2016, 214, 386-395. [CrossRef] [PubMed]

48. Subathra, M.S.P.; Selvan, S.E.; Victoire, T.A.A.; Christinal, A.H.; Amato, U. A Hybrid with Cross-Entropy Method and Sequential Quadratic Programming to Solve Economic Load Dispatch Problem. IEEE Syst. J. 2014, 9, 1031-1044. [CrossRef]

49. Chaudhry, F.A.; Amin, M.; Iqbal, M.; Khan, R.D.; Khan, J.A. A novel chaotic differential evolution hybridized with quadratic programming for short-term hydrothermal coordination. Neural Comput. Appl. 2018, 30, 3533-3544. [CrossRef]

50. Sun, Z.; Tian, Y.; Li, H.; Wang, J. A superlinear convergence feasible sequential quadratic programming algorithm for bipedal dynamic walking robot via discrete mechanics and optimal control. Optim. Control. Appl. Methods 2015, 37, 1139-1161. [CrossRef]

51. Pasandideh, S.H.R.; Niaki, S.T.A.; Gharaei, A. Optimization of a multiproduct economic production quantity problem with stochastic constraints using sequential quadratic programming. Knowl. Based Syst. 2015, 84, 98-107. [CrossRef]

52. Wahl, P.E.; Løvseth, S.W. Formulating the optimization problem when using sequential quadratic programming applied to a simple LNG process. Comput. Chem. Eng. 2015, 82, 1-12. [CrossRef]

53. Xiao, C.-L.; Huang, H.-X. Optimal design of heating system in rapid thermal cycling blow mold by a two-step method based on sequential quadratic programming. Int. Commun. Heat Mass Transf. 2018, 96, 114-121. [CrossRef]

54. Engelbrecht, J.J.; Engelbrecht, J.A. Optimal attitude and flight vector recovery for large transport aircraft using sequential quadratic programming. In Proceedings of the 2016 Pattern Recognition Association of South Africa and Robotics and Mechatronics International Conference (PRASA-RobMech), Stellenbosch, South Africa, 30 November-2 December 2016; pp. 1-7.

55. Schröder, K.; Gebhardt, C.; Rolfes, R. Damage Localization at Wind Turbine Support Structures Using Sequential Quadratic Programming for Model Updating. In Proceedings of the 8th European Workshop on Structural Health Monitoring, Bilbao, Spain, 5-8 July 2016.

56. Etoa, J.B.E. Solving convex quadratic bilevel programming problems using an enumeration sequential quadratic programming algorithm. J. Glob. Optim. 2009, 47, 615-637. [CrossRef]

57. Sanchez, Y.G. Design of a Nonlinear SITR Fractal Model Based on the Dynamics of a Novel Coronavirus (COVID). Fractals 2020, $28,2040026$.

58. Sánchez, G.; Sabir, Z.; Günerhan, H.; Baskonus, H.M. Analytical and Approximate Solutions of a Novel Nervous Stomach Mathematical Model. Discret. Dyn. Nat. Soc. 2020, 2020. [CrossRef]

59. Sabir, Z.; Imran, A.; Umar, M.; Zeb, M.; Shoaib, M.; Raja, M.A.Z. A numerical approach for two-dimensional Sutterby fluid flow bounded at a stagnation point with an inclined magnetic field and thermal radiation impacts. Therm. Sci. 2020, 186. [CrossRef]

60. Umar, M.; Sabir, Z.; Imran, A.; AbdulWahab, H.; Shoaib, M.; Raja, M.A.Z. Three-dimensional flow of Casson nanofluid over a stretched sheet with chemical reactions, velocity slip, thermal radiation and Brownian motion. Therm. Sci. 2020, 24, 2929-2939. [CrossRef] 
61. Sabir, Z.; Akhtar, R.; Zhiyu, Z.; Umar, M.; Imran, A.; Wahab, H.A.; Shoaib, M.; Raja, M.A.Z. A Computational Analysis of Two-Phase Casson Nanofluid Passing a Stretching Sheet Using Chemical Reactions and Gyrotactic Microorganisms. Math. Probl. Eng. 2019, 2019, 1490571. [CrossRef]

62. Umar, M.; Akhtar, R.; Sabir, Z.; Wahab, H.A.; Zhiyu, Z.; Imran, A.; Shoaib, M.; Raja, M.A.Z. Numerical treatment for the three-dimensional eyring-powell fluid flow over a stretching sheet with velocity slip and activation energy. Adv. Math. Phys. 2019, 2019, 9860471. [CrossRef]

63. Sabir, Z.; Ayub, A.; Guirao, J.L.; Bhatti, S.; Shah, S.Z.H. The Effects of Activation Energy and Thermophoretic Diffusion of Nanoparticles on Steady Micropolar Fluid along with Brownian Motion. Adv. Mater. Sci. Eng. 2020, 2020, 2010568. [CrossRef] 